\title{
Genetically Optimized FACTS Controllers for Available Transfer Capability Enhancement
}

\author{
J. Vara Prasad \\ Assistant Professor \\ Dept.of Electrical \&Electronics \\ GGITM, Bhopal (M.P.), India
}

\author{
I. Sai Ram \\ Assistant Professor \\ Dept.of Electrical \&Electronics \\ DIET, Vijayawada (A.P), India
}

\author{
B. Jayababu \\ Associate Professor \\ Dept.of Electrical \&Electronics \\ VLITS, Guntur (A.P), India
}

\begin{abstract}
Improving of Available Transfer Capability (ATC) is an important issue in the current de-regulated environment of power systems. Power transactions between a specific seller bus/area and a buyer bus/area can be committed only when sufficient ATC is available. It is well known that Flexible AC Transmission Systems (FACTS) technology can control voltage magnitude, phase angle and circuit reactance. Using these devices may redistribute the load flow, regulating bus voltages. Therefore, it is worthwhile to investigate the impact of FACTS controllers on the ATC. In this paper focuses on the evaluation of the impact of Thyristor Controlled Series Capacitor (TCSC) and Static Var Compensator (SVC) as FACTS devices on ATC and its enhancement during with and without line outage cases. Real-code Genetic Algorithm (RGA) is used as the optimization tool to determine the location as well as the controlling parameter of TCSC or SVC simultaneously. The performance of the Real-code Genetic Algorithm has been tested on IEEE 24Bus Reliability Test System.
\end{abstract}

\section{Keywords}

De-regulated power system, ATC, TCSC, SVC, RGA

\section{INTRODUCTION}

The aim of electric industry restructuring is to promote competitive markets for electric power trading. Under new environment, the main consequence of the nondiscriminatory open-access requirement is the substantial increase in power transfers. The Available Transfer Capability (ATC) of a transmission network is the unutilized transfer capabilities of a transmission network for the transfer of power for further commercial activity, over and above already committed usage. Adequate Available Transfer Capacity (AATC) is needed to ensure all economic transactions, while sufficient ATC is needed to facilitate electricity market liquidity. It is necessary to maintain economical and secure operation over a wide range of system operating conditions and constraints. However, tight restrictions in the construction of new facilities due to the economic, environmental, and social problems, reduces the operational alternatives. It may sometimes lead to a situation that the existing transmission facilities are intensively used. On the other hand it can be said that power suppliers will benefit from more market opportunities with reduced possibility of congestion incorporating power systems security enhancement. Maximum use of existing transmission assets will be more profitable for transmission system owners and customers will receive better services with reduced prices [1].
Based upon the NERC's definition of ATC and its determination [2], transmission network can be restricted by thermal, voltage and stability limits. On the other hand, it is highly recognized that, with the capability of flexible power flow [3], FACTS technology has introduced a severe impact to the transmission system utilization with regards to those three constraints. From the steady state power flow viewpoint, networks do not normally share power in proportion to their ratings, where in most situations, voltage profile cannot be smooth. Therefore, ATC values are always limited by heavily loaded buses with relatively low voltage.

FACTS concept makes it possible to use circuit reactance, voltage magnitude, and phase angle as controls to redistribute line flow and regulate voltage profile. Theoretically FACTS devices can offer an effective and promising alternative to conventional methods of ATC enhancement. They will provide new control facilities, both in steady state power flow control and dynamic stability control [4]. Controlling power flow in electric power systems without generation rescheduling or topological changes can improve the network performance considerably. In this paper, with suitable location, the effect of a TCSC and SVC on the ATC enhancement are studied and demonstrated through case studies. It is to be shown that, installing SVC in the proper location will improve voltage profile as well as ATC, and TCSC will improve the ATC by reducing transmission congestion.

\section{EVALUATION OF ATC}

For ATC determination the MW flows must be allocated to each line or group of lines in proportion to the MWs being transmitted by each transaction. This is accomplished through the use of the linear Power Transfer Distribution Factors (PTDF) $[5,6]$. A transaction is defined by a 4 tipple $\left(t, i, j, P_{t}\right)$ where $\mathrm{t}$ is the transaction number, $i$ and $j$ are the source and sink nodes and $P_{t}$ is the MWs transacted. The change in flow for an arbitrary line $l-m$ can be evaluated by sensitivity analysis as follows.

$$
\Delta P_{l m}=\left[\frac{\partial P_{l m}}{\partial \delta_{2}}, \ldots, \frac{\partial P_{l m}}{\partial \delta_{n}}, \frac{\partial P_{l m}}{\partial V_{g+1}}, \ldots, \frac{\partial P_{l m}}{\partial V_{n}}\right]\left[\begin{array}{c}
\Delta \delta_{2} \\
\cdot \\
\dot{\delta_{n}} \\
\Delta\left|V_{g+1}\right| \\
\cdot \\
\Delta \cdot V_{n} \mid
\end{array}\right]
$$


From the converged base case load flow solution we have

$$
\left[\begin{array}{c}
\Delta \delta_{2} \\
\cdot \\
\dot{\delta_{n}} \\
\Delta\left|V_{g+1}\right| \\
\cdot \\
\dot{V_{n} \mid}
\end{array}\right]=\left[J^{-1}\right]\left[\begin{array}{c}
\Delta \delta_{2} \\
\cdot \\
\dot{\delta_{n}} \\
\Delta\left|V_{g+1}\right| \\
\cdot \\
\cdot \\
\Delta\left|V_{n}\right|
\end{array}\right]
$$

Where $J$ is load flow Jacobian. For a MW power transaction number $t$,

$\Delta P_{i}=+P_{t}$

$\Delta P_{j}=-P_{t}$

$\Delta P_{k}=0$

$\Delta Q_{i}=0$

where $(k=1 \ldots n, k \neq i, j)$. Substituting (3) in R.H.S. of (2) and then revised (ii) in (i) we have

$$
\begin{aligned}
& \Delta P_{l m}=\left[\frac{\partial P_{l m}}{\partial \delta_{2}}, \ldots, \frac{\partial P_{l m}}{\partial \delta_{n}}, \frac{\partial P_{l m}}{\partial V_{g+1}}, \ldots, \frac{\partial P_{l m}}{\partial V_{n}}\right]\left[J^{-1}\right]\left[\begin{array}{c}
0 \\
\cdot \\
\cdot \\
+P_{t} \\
0 \\
. \\
-P_{t} \\
0
\end{array}\right] \\
& =d_{t} P_{t}
\end{aligned}
$$

Where $d_{t}$ is the PTDF. The effect of multiple transactions (not necessarily disjoint) in the flow of line $l-m$ can be obtained by superposition i.e. for $t_{k}$ transactions we have

$$
\Delta P_{l m}=d_{t 1} P_{t 1}+d_{t 2} P_{t 2}+\cdots+d_{t k} P_{t k}
$$

ATC is determined by recognizing new flow on line from node $l$ to node $m$, due to a transaction from node $i$ to node $j$.The new flow on the line is sum of original flow $P_{l m}^{0}$ and the change.

$$
P_{l m}^{N e w}=P_{l m}^{0}+d_{l m, i j} P_{i j}
$$

where $d_{l m, i j}$ is the PTDF for line $l m$ due to transaction $i j, P_{l m}^{0}$ is the base case flow on the line, and $P_{i j}$ is the magnitude of the proposed transfer. If the limit on line $I m$, the maximum power that can be transferred without overloading line $l m$, is $P_{l m}^{\max }$ then

$$
P_{i j, l m}^{\max }=\frac{P_{l m}^{\max }-P_{l m}^{0}}{d_{l m, i j}}
$$

$P_{i j, l m}^{\max }$ is the maximum allowable transaction from node $i$ to node $j$ constrained by line from node $l$ to node $m$. ATC is the minimum of the maximum allowable transactions over all lines.

$$
A T C_{i j}=\min _{l m} P_{i j, l m}^{\max }
$$

\section{MODELING OF TCSC \& SVC}

\subsection{TCSC}

Transmission lines are represented by lumped $\pi$ equivalent parameters. The series compensator TCSC is simply a static capacitor/reactor with impedance $j X c$ [7]. Fig. 1 shows a transmission line incorporating a TCSC.

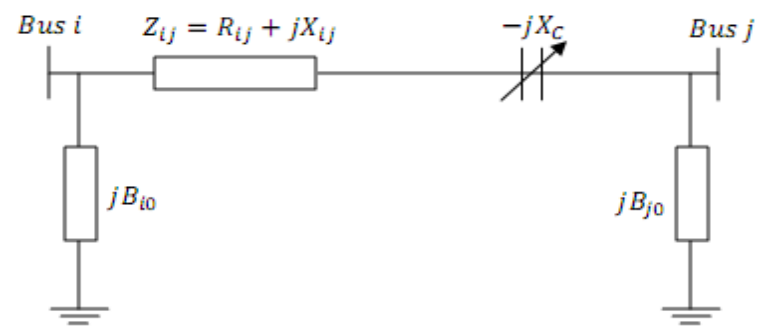

Fig 1: Equivalent circuit of a line with TCSC.

where $X_{i j}$ is the reactance of the line, $R_{i j}$ is the resistance of the line, $B_{i o}$ and $B_{j o}$ are the half-line charging susceptance of the line at bus- $i$ and bus- $j$. The difference between the line susceptance before and after the addition of TCSC can be expressed as:

$$
\begin{aligned}
& \Delta y_{i j}=y_{i j}^{\prime}-y_{i j}=\left(g_{i j}^{i}+j b_{i j}^{\prime}\right)-\left(g_{i j}+j b_{i j}\right) \\
& g_{i j}^{i}=\frac{R_{i j}}{\sqrt{R_{i j}^{2}+\left(X_{i j}-X_{c}\right)^{2}}}, b_{i j}^{\prime}=-\frac{X_{i j}}{\sqrt{R_{i j}^{2}+\left(X_{i j}-X_{C}\right)^{2}}} \\
& g_{i j}=\frac{R_{i j}}{\sqrt{R_{i j}^{2}+X_{i j}^{2}}}, b_{i j}=-\frac{X_{i j}}{\sqrt{R_{i j}^{2}+X_{i j}^{2}}}
\end{aligned}
$$

After adding TCSC in the line between bus $i$ and bus $j$ of a general power system, the new system admittance matrix $Y_{\text {bus }}^{\prime}$ can be updated as

$$
Y_{b u s}=Y_{b u s}+\left[\begin{array}{cccc}
0 & 0 & 0 & 0 \\
0 & \Delta y_{i j} & -\Delta y_{i j} 0 \\
0 & 0 & 0 & 0 \\
: & : & : & : \\
0 & 0 & 0 & 0 \\
0-\Delta y_{i j}-\Delta y_{i j} & 0 \\
0 & 0 & 0 & 0
\end{array}\right]
$$

\subsection{SVC}

The Shunt Compensator SVC is simply considered as a static capacitor/reactor with susceptance $B_{\text {svc. }}$ Fig.2 shows the equivalent circuit of the SVC can be modeled as a shuntconnected variable susceptance $\mathrm{B}_{\mathrm{svc}}$ at bus- $i$. 


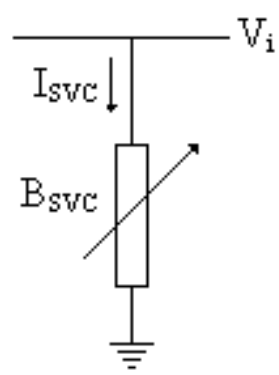

Fig 2: Variable shunt susceptance

The reactive power injected into the bus due to SVC can be expressed as

$Q_{S V C}=B_{S V C} V_{i}^{2}$

where $V_{i}$ is the voltage magnitude of the bus at which the SVC is connected. After adding SVC at bus- $i$ of a general power system, the new system admittance matrix $Y^{\prime}$ bus can be updated as

$$
Y_{b u s}=Y_{b u s}+\left[\begin{array}{cccccc}
0 & 0 & \ldots & 0 & 0 & 0 \\
0 & y_{s h} & \ldots & 0 & 0 & 0 \\
0 & 0 & & 0 & 0 \\
: & : & & & : & : \\
0 & 0 & & 0 & 0 \\
0 & 0 & \ldots & 0 & 0 \\
0 & 0 & \ldots & 0 & 0 & 0
\end{array}\right]
$$

\section{IMPLEMENTATION OF RGA}

In this paper, Real code Genetic Algorithm is used. Compared with binary GA, it offers higher accuracy of the control variables. The method can be summarized in following three steps. The detailed description can be found in [8].

\subsection{Predictor}

Given an initial operating point, the next point in system variables is found by choosing the tangent to the system trajectory and a step length.

\subsection{Corrector}

Using the solution of the above step as the starting point, intersection between the perpendicular plane to the tangent vector and the systems solution trajectory is found.

\subsection{Parameterization}

Checking the relative change in all the system variables, the appropriate parameter is selected.

When TCSC is incorporated in the system, if we consider all lines of the IEEE24-Bus Reliable Test System, there are 38 possible locations for the TCSC. The location code region are set as 38 integers as 1 to 38 . The amount of compensation offered by TCSC is 0 to $40 \%\left(K_{d}\right)$. And when one SVC is incorporated in the system, if we consider all buses of system, there are 24 possible locations for the SVC. The location code region are set as 24 integers as 1 to 24 . The amount of compensation offered by SVC is 0 to 0.1 (p.u) i.e., $B_{\text {svc }}$.

In this work, ACPTDF are used to determine the amount of ATC, which satisfies the line thermal limits and bus voltage magnitude limits. For a specific source/sink transfer case, the steps for calculating the ATC may be summarized as:

- Specify Continuation parameters.

- Predictor operation with Jacobin matrix obtained by step 1 .

- Corrector operation by solving power flow equation with updated Jacobin matrix.

- Check the solution of step 3 for violations of constraints. If there are violations, return the power flow solutions of the previous step and terminate the program. If not, recycle the step 2-4 until a violation occurs.

\section{RESULTS}

Determination of ATC with Real Coded Genetic Algorithm is tested on the IEEE-24 bus system. With the implementation of RGA, the optimal location of TCSC/SVC and their compensation levels are determined. AC Power Transfer Distribution Factors (ACPTDF) are used to calculate ATC value with and without contingencies for a set of source/sink transfer. The ATC values obtained for different transactions and their enhanced values with TCSC and SVC devices are presented in Tables 1 and 2 respectively. Due to the system limits it is very difficult to find a base case that is reliable under all line contingencies, only one of the credible line contingency results are presented Table 3.

The ATC values obtained for different transactions with single line outage (i.e. line -8 ) and their enhanced values with TCSC and SVC devices are presented in Tables 3 and 4 respectively. From Table I, II, III and IV, it can be concluded that for a specific transaction between source bus to sink bus, the ATC value is limited by

- Maximum MW flow constraint for a line, if the system is incorporated with TCSC.

- Minimum voltage constraint for a bus, if the system is incorporated with SVC.

- The enhanced ATC values are dependent on the type of FACTS device used and its location as well as compensation value.

- The system operating condition, i.e. normal or with outage condition

For better understanding of voltage support done by the SVC under line- 8 outage condition, the voltage magnitudes at all busses are presented in Fig. 3

Table 1. ATC values incorporating TCSC

\begin{tabular}{|c|c|c|c|c|}
\hline $\begin{array}{c}\text { Source/Sink } \\
\text { Bus No }\end{array}$ & $\begin{array}{c}\text { ATC } \\
\text { without } \\
\text { TCSC } \\
\text { (MW) }\end{array}$ & $\begin{array}{c}\text { ATC } \\
\text { with } \\
\text { TCSC } \\
\text { (MW) }\end{array}$ & $\begin{array}{c}\text { TCSC } \\
\text { location }\end{array}$ & $\begin{array}{c}\text { Compensation } \\
\text { Value (p.u.) }\end{array}$ \\
\hline $23 / 15$ & 770.0 & 810.0 & Line - 28 & -0.0103 \\
\hline
\end{tabular}




\begin{tabular}{|c|c|c|c|c|}
\hline $22 / 9$ & 395.0 & 420.0 & Line - 12 & -0.0635 \\
\hline $22 / 5$ & 265.0 & 270.0 & Line - 15 & -0.0239 \\
\hline $21 / 6$ & 105.0 & 120.0 & Line - 5 & -0.0669 \\
\hline $18 / 5$ & 260.0 & 270.0 & Line - 15 & -0.0283 \\
\hline
\end{tabular}

\begin{tabular}{|c|c|c|c|c|}
\hline $21 / 6$ & 86.7 & 91.8 & Line -7 & -0.0730 \\
\hline $18 / 5$ & 214.2 & 229.5 & Line - 2 & -0.0328 \\
\hline
\end{tabular}

Table 2. ATC values incorporating SVC

\begin{tabular}{|c|c|c|c|c|}
\hline $\begin{array}{c}\text { Source/Sink } \\
\text { Bus No }\end{array}$ & $\begin{array}{c}\text { ATC } \\
\text { without } \\
\text { SVC } \\
\text { (MW) }\end{array}$ & $\begin{array}{c}\text { ATC } \\
\text { with } \\
\text { SVC } \\
\text { (MW) }\end{array}$ & $\begin{array}{c}\text { SVC } \\
\text { location }\end{array}$ & $\begin{array}{c}\text { Compensation } \\
\text { Value (p.u.) }\end{array}$ \\
\hline $23 / 15$ & 770.0 & 790.9 & Bus - 20 & 0.099 \\
\hline $22 / 9$ & 395.0 & 405.0 & Bus - 5 & 0.086 \\
\hline $22 / 5$ & 265.0 & 265.0 & Bus - 11 & 0.081 \\
\hline $21 / 6$ & 105.0 & 110.0 & Bus - 11 & 0.082 \\
\hline $18 / 5$ & 260.0 & 262.0 & Bus - 5 & 0.091 \\
\hline
\end{tabular}

Table 4. ATC values incorporating SVC with line-8 outage

\begin{tabular}{|c|c|c|c|c|}
\hline $\begin{array}{c}\text { Source/Sink } \\
\text { Bus No }\end{array}$ & $\begin{array}{c}\text { ATC } \\
\text { without } \\
\text { SVC } \\
\text { (MW) }\end{array}$ & $\begin{array}{c}\text { ATC } \\
\text { with } \\
\text { SVC } \\
\text { (MW) }\end{array}$ & $\begin{array}{c}\text { SVC } \\
\text { location }\end{array}$ & $\begin{array}{c}\text { Compensation } \\
\text { Value (p.u.) }\end{array}$ \\
\hline $23 / 15$ & 765.0 & 785.40 & Bus - 10 & 0.084 \\
\hline $22 / 9$ & 385.0 & 392.7 & Bus - 23 & 0.099 \\
\hline $22 / 5$ & 214.0 & 219.3 & Bus - 14 & 0.092 \\
\hline $21 / 6$ & 86.7 & 88.2 & Bus -6 & 0.081 \\
\hline $18 / 5$ & 214.2 & 224.40 & Bus - 16 & 0.098 \\
\hline
\end{tabular}

Table 3. ATC values incorporating TCSC with line-8 outage

\begin{tabular}{|c|c|c|c|c|}
\hline $\begin{array}{c}\text { Source/Sink } \\
\text { Bus No }\end{array}$ & $\begin{array}{c}\text { ATC } \\
\text { without } \\
\text { TCSC } \\
\text { (MW) }\end{array}$ & $\begin{array}{c}\text { ATC } \\
\text { with } \\
\text { TCSC } \\
\text { (MW) }\end{array}$ & $\begin{array}{c}\text { TCSC } \\
\text { location }\end{array}$ & $\begin{array}{c}\text { Compensation } \\
\text { Value (p.u.) }\end{array}$ \\
\hline $23 / 15$ & 765.0 & 801.2 & Line - 25 & -0.0101 \\
\hline $22 / 9$ & 385.0 & 413.1 & Line - 14 & -0.0652 \\
\hline $22 / 5$ & 214.0 & 229.5 & Line - 2 & -0.0304 \\
\hline
\end{tabular}

\section{CONCLUSIONS}

Implementation of the Real code Genetic Algorithm has performed well when it is used to determine the location and compensation level of TCSC or SVC with the aim of maximizing the Available Transfer Capability. From the results, it is shown that installing SVC as a FACTS device will improve voltage profile as well as resulting ATC enhancement, where as TCSC can improve ATC in both thermal dominant case and voltage dominant case. Finally, it is clearly shows from the results that TCSC is more effective than SVC in improving ATC under both normal and contingency conditions.

\section{ACKNOWLEDGMENTS}

The authors wish to thank the Management of GGITM, Bhopal and principal, Dr.P.S.Venkataramu for their constant encouragement to this work. 
[4] Wang Feng, G.B.Shrestha "Allocation of TCSC Devices to Optimize Total Transmission Capacity in a Competitive Power Market" IEEE Trans. Power Systems, Feb 2001, 587-592.

[5] Allen J. Wood and Bruce F. Wollenberg, "Power Generation, Operation and Control", John Wiley and Sons, New York, NY, 1984.

[6] A.Fradi, S.Brignone, B.F.Wollenberg,"Calculation of Energy Transaction Allocation Factors", IEEE Trans. On Power Systems, vol. 16, no. 2, pp267-272, May 2001.
[7] Stephane Gerbex, Rachid Cherkaoui, and Alain J. Germond, "Optimal Location of Multi-Type FACTS Devices in a Power System by Means of Genetic Algorithms," IEEE Trans. on Power Systems, vol. 16, no. 3, August 2001

[8] Vladimiro Miranda, J.V. Ranito, L. M. Proenca, "Genetic Algorithms in Optimal Multistage Distribution Network Planning", IEEE Tran. Power Systems, Vol. 9, No. 4, Nov. 1994, 1927-1933. 